\title{
Construction Cost Overruns of Residential Building Projects in Oman: Root Cases and Mitigation Strategy
}

\author{
Mohammed Al Jabri ${ }^{1}$ and Mahmoud Dawood ${ }^{1 \#}$ \\ ${ }^{1}$ Middle East College, Muscat, Oman \\ \#Advisor
}

\section{ABSTRACT}

Characteristics of construction project includes a specific purpose and it must meet the requirements and expectations of the client. The construction project activities are always linked together and the time required for each activity does vary. The working on the project will not complete unless there are experts from different departments ranging from site workers, civil engineers, architects, electricians, designers, project engineer, site engineer, project manager and administrative staff such as procurement department and others. One of the primary objectives is to finish the project within budget. Excess of construction costs has a negative impact on project parties. Therefore, the causes of these abuses must be identified, especially in the Sultanate of Oman. This research investigates and evaluates the root causes of the cost overrun, cost trend and financial risks related to the residential projects in Sultanate of Oman. A questionnaire has been designed to collect the primary data and literatures are studied to collect the related secondary data. The causes are categorized into three groups according to the responses of the specialists with the contractor, consultant and client .Aspects of agreement between groups were identified after analyzing the questionnaire.

\section{Introduction}

When the project cost objectives are not achieved with respect to the cost plan and allocated budget, this is known as cost overrun. According to the literature, in global construction, it is observed that 9 out of 10 projects had overrun. The problem of cost overruns exists in construction industry of all countries (Reina \& Angelo, 2002). Therefore, it has to be studied to mitigate the effects of this problem on projects. The percentage of exceeding construction costs varies from country to another or from one project to another, according to the accuracy of the details and good management of resources. Sultanate of Oman faces problems related to cost overruns in projects, especially in government and residential projects. This research focuses on housing projects to find out what are the reasons for the increasing costs.

All these sections must be properly coordinated so that project activities could be organized and implemented smoothly. These individuals are supposed to acquire new skills from different projects. The execution of the project is supposed to be within the allocated budget. Most importantly, the construction plans should be flexible to accommodate any variations that may occur during the execution of the task and recognizes that there are many risks in every phase. In addition, it is mandatory that the project manager should has sufficient knowledge of how to manage these associated risks (Memon et al., 2011).

This research focuses on is the factors that cause cost overruns, cost trend and financial risks of residential building in Sultanate of Oman and their impact on efficiency in the construction sector. There are challenges facing contractors, small or large, in construction projects, which are poor management of construction, delayed payments by the owner and experienced workers. In addition, some researches confirm that the equipment related issues and materials prices are among the reasons that cause cost overrun. All of these factors directly affect time, quality and 
cost and it may cause failure for the project. Usually knowing how to manage the project is a major reason to reduce the influence of factors on the project. All resources and methods necessary to implement the project must be identified without any risks that may affect the project. Time, cost and quality are the main factors that relate to project success when properly managed, and they are through planning, coordination and full monitoring of all phases of the project. Project management requires knowledge and experience in the field in order to achieve the goal of the project.

\section{Cost Overrun: General Overview}

Construction industry is one of the key sectors in developing the country (Alzahrani \& Emsley, 2013). Therefore, it is very significant to ensure that the project is completed without any problem as one of the challenges in the construction project is the cost overrun. Based on the literature, 250 projects were covered in a related survey in different 18 countries. As a result for the conducted survey, approximate $87 \%$ of the project explain the significant of the cost overrun. Also, in the survey appear $20 \%$ mounting the cost in the big project. According to the survey, cost overrun the most significant and common factor (Plebankiewicz, 2018). Cost overrun is a common problem in all countries. The size, type of the project, additional work and productivity of the worker are the main factors that affect the cost overrun.

Aljohani et al. (2017) summarized the reason of the cost overrun in the residential project in two factors internal factors and external factors. Under these two factors, there are many root causes for cost overrun. For example, projects owner, projects contractor and projects consultant all these causes under the internal factors. Economic, system and weather these under external factor. Aljohani et al. (2017) classified the reasons affecting cost overruns into three groups: management factors, and macroeconomic factors and business and regulatory environment. Shehu et al. (2014) analyzed the main factors causing cost overruns in construction industry. It includes variations in materials' cost as prices of materials are increase due to continuous border closures, delay in construction, supply of raw materials and equipment by contractors, project materials monopoly by some traders, resources constraint, lack of cost monitoring during contract stages, funds and related auxiliaries not prepared, design changes and inaccurate quality take-off.

In developed countries, the impact of cost overruns can be more serious and the results can sometimes exceed $100 \%$ of the estimated initial project (Kim et al., 2020). The construction industry is one of the key sectors to stimulate and evaluate the necessary components to improve the country's economy. Therefore, the building has a great touch and plays an important role in economic growth or revitalization in all countries. Jia (2015) investigated the factors of cost overrun. These factors include (not limited to) are lack of project management during execution, ineffective working, delays, changes in scope of work and location and law. Siemiatycki (2018) briefly states that political and economic cause cost overrun in construction projects in Canada. Abdel-Hafeez et al. (2016) identified the factors cause cost overrun in Egypt. These sources are material prices, changes the scope, poor estimation, additional works by owner's request, bidding to the lowest price, increasing the cost of building materials and completion time. Figure 1 shows the causes of cost overrun in construction industry (Subramani et al., 2014, Abusafiya \& Suliman, 2017). These include, project management, planning, estimation, designs, contracts, materials, equipment, work force, communication, and financial issues. 


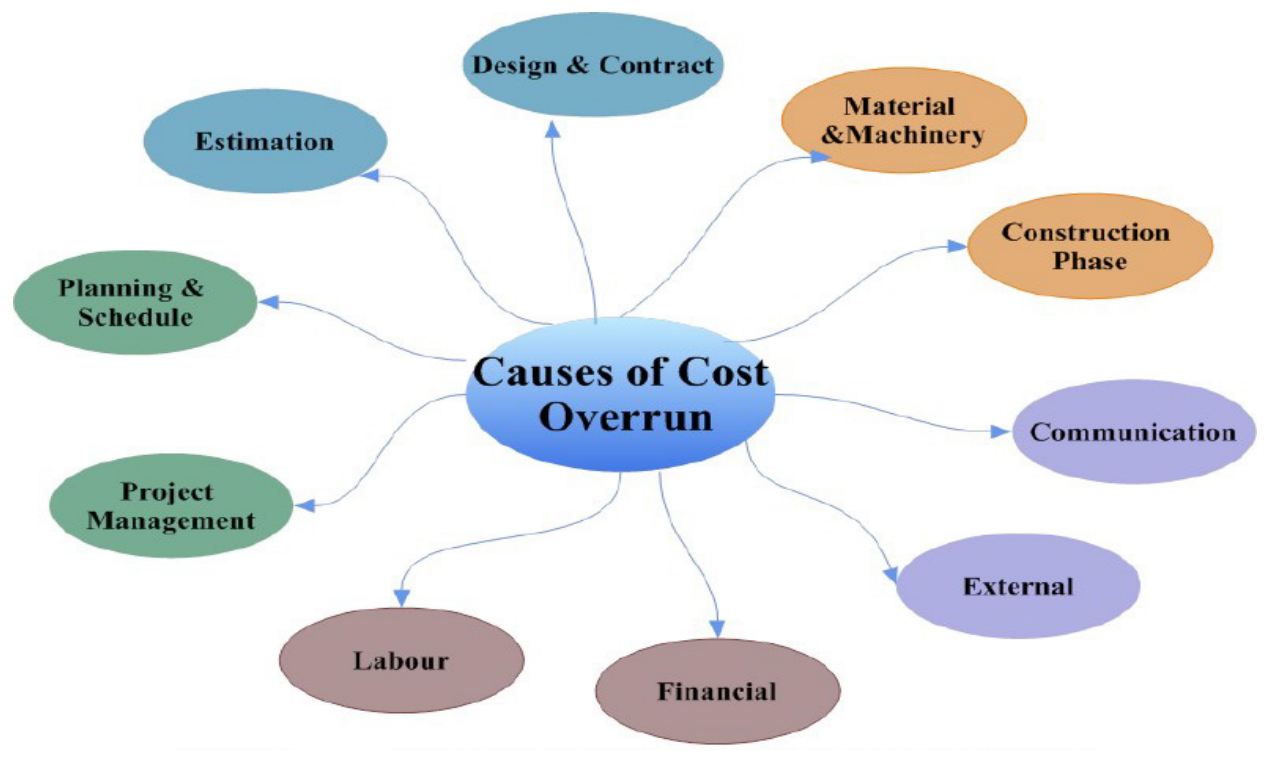

Figure 1: General root causes of construction cost overrun (Subramani et al., 2014)

\section{Research Method}

The adopted approach is the mix methodology which is a combination from quantitative and qualitative (Reiter et al., 2010). It includes the quantitative data collection that can be analyzed in an accurate way to obtain characteristics and relationships. Quantitative approach is concerned with studying population samples to obtain real answers from the data. While the qualitative approach aims at opinions and behavior to obtain a self-evaluation of the question (Daniel, 2016). The variables and factors are provided using the quantitative approach. As introduced, the aim of this research is to investigate the reasons that affect the overrun cost of construction in housing projects in the Sultanate of Oman. Moreover, the quantitative approach aims to confirm the existing theories .To develop a specific phenomenon statistic are collected and the quantitative approach is used.

The qualitative and qualitative approaches used in this research have been carried out in several stages. These stagers include defining the problem, studying the literature, research method, collecting data, analyzing the data, providing results and presentation. The research approach aims to evaluate the reasons that lead to cost overrun in construction residential projects in the Sultanate of Oman.

The target population to find out the factors that cause cost overrun in construction projects of residential buildings in Sultanate of Oman. Both the public sector and the private sector are categories of respondents. The private sector focused on the owners of small and medium enterprises in the field of construction in Muscat. For public sector, it focused on work in the construction department . The people most involved in construction activities are targeted in this research. The adopted sample based on the design is 248 .

More than fifty variables have been identified in the literature. However, approximately thirty factors are relevant to this research. Some factors are investigated according to personal experience and opinion of future experts. Factors are grouped so that the participant can easily provide appropriate feedback. Among these groups are the owner, contractor, consultant, materials, work force, external causes, and design. Factors related to a specific project are often derived from contract documents, such as type of contract, project duration, non-reward, etc .Also, among the factors that produce cost overrun is lack of commitment to responsibilities, interference with responsibilities and lack of coordination between activities .Among the contractual responsibilities of the king is the provision of location, approvals, and financial affairs. Among the factors related to the contractor are contractor poor performance, failure to 
evaluate the site in an accurate manner, and lack of resources.The factors that result from the design are summarized into four aspects: design flaws, delays in testing, slow correction and late review of drawings.

\section{Root Causes of Cost Overrun}

Figure 1 indicates that the study agrees on all items of causes of cost overrun in residential project. Figure 2 indicates that the sample study has moderate impact on all items of impact of cost overrun in residential project. Figure 3 indicates the factors that represents the appropriate action strategy in order to reduce the negative impacts of mange the cost overrun issue.

Design stage is one of the initial stages of the project, in which the detailed drawings and the plan are prepared at this stage (Roslan et al., 2015). The design stage is considered as an important stage in the project life cycle. To avoid cost overruns, due consideration must be given to the design phase. Design change, design errors, incomplete design, short time for bid preparation, inadequate planning and scheduling, delay in decision-making, and lack of experience are the root causes of cost overrun based on the design stage (Stuchlík, 2018). In addition, effective and accurate project information must be available from all sides in order to facilitate project assessment. Accuracy of estimate gives a realistic estimate of cost and time for a project (Al-Hazim \& Salem, 2015). Project needs planning includes all operations in the project cycle stages. Successful and appropriate project planning is very important factor in minimizing cost overrun issues. In addition, manpower, machines, financial, materials and construction related factors have been identified as primary factor in effecting on construction cost. 


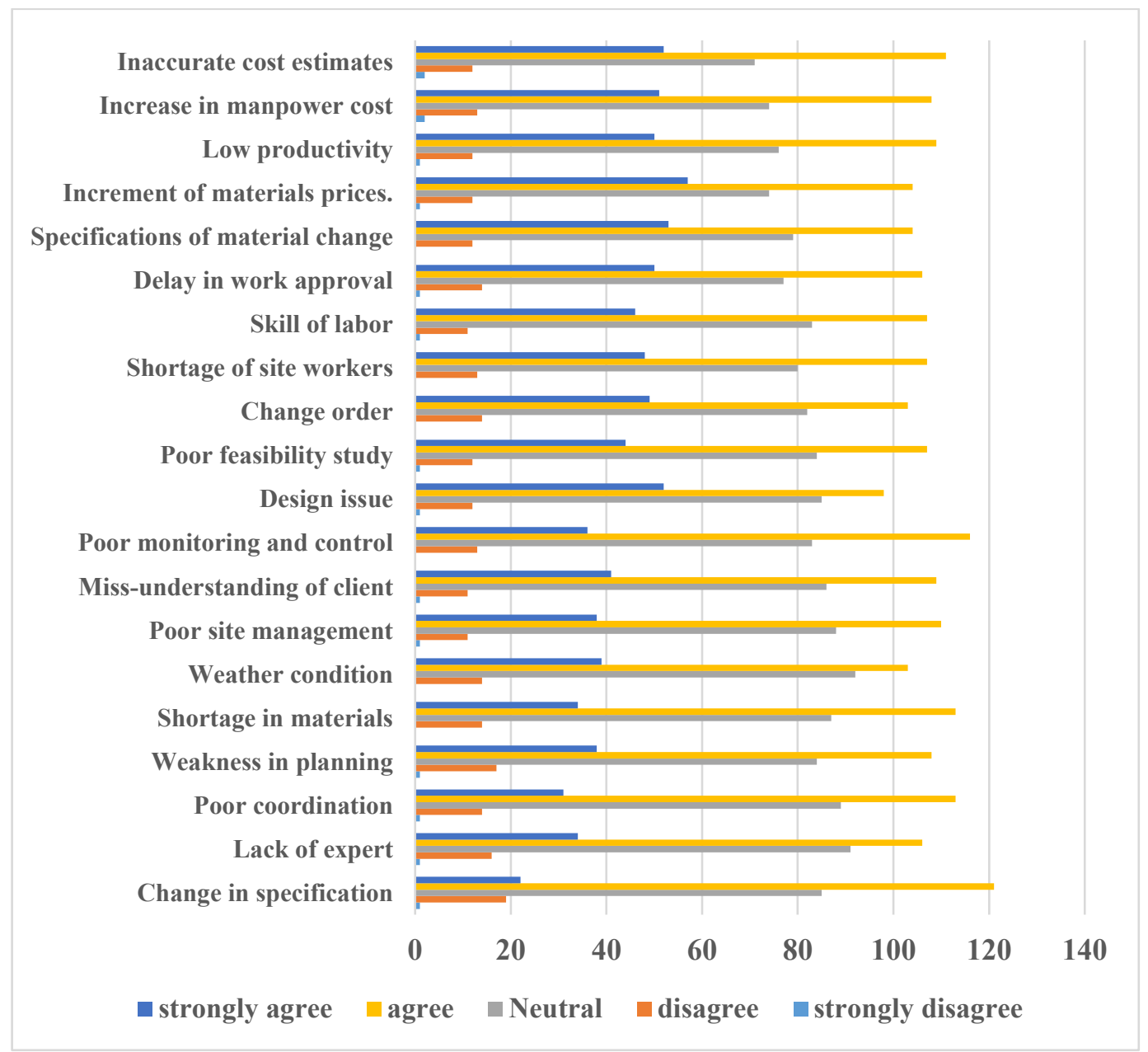

Figure 1: Root causes of cost overrun in residential projects in Sultanate of Oman

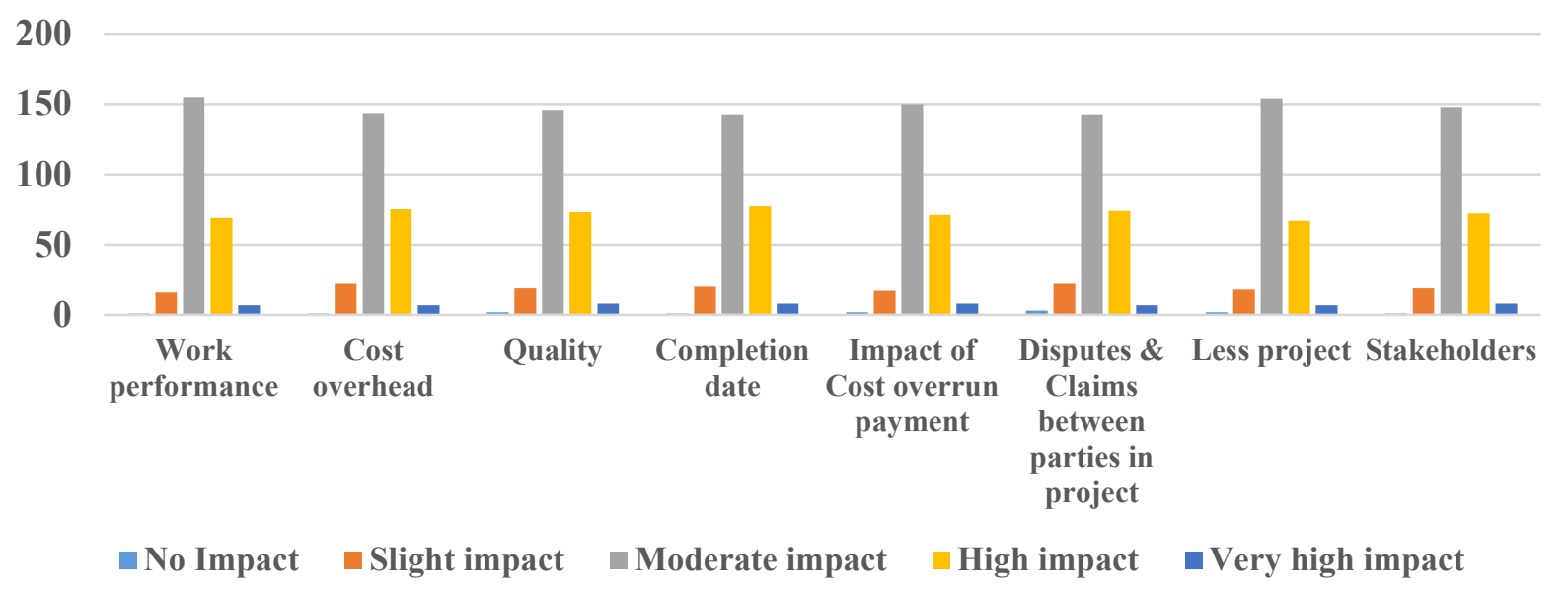

Figure 2: Impacts of cost overrun 


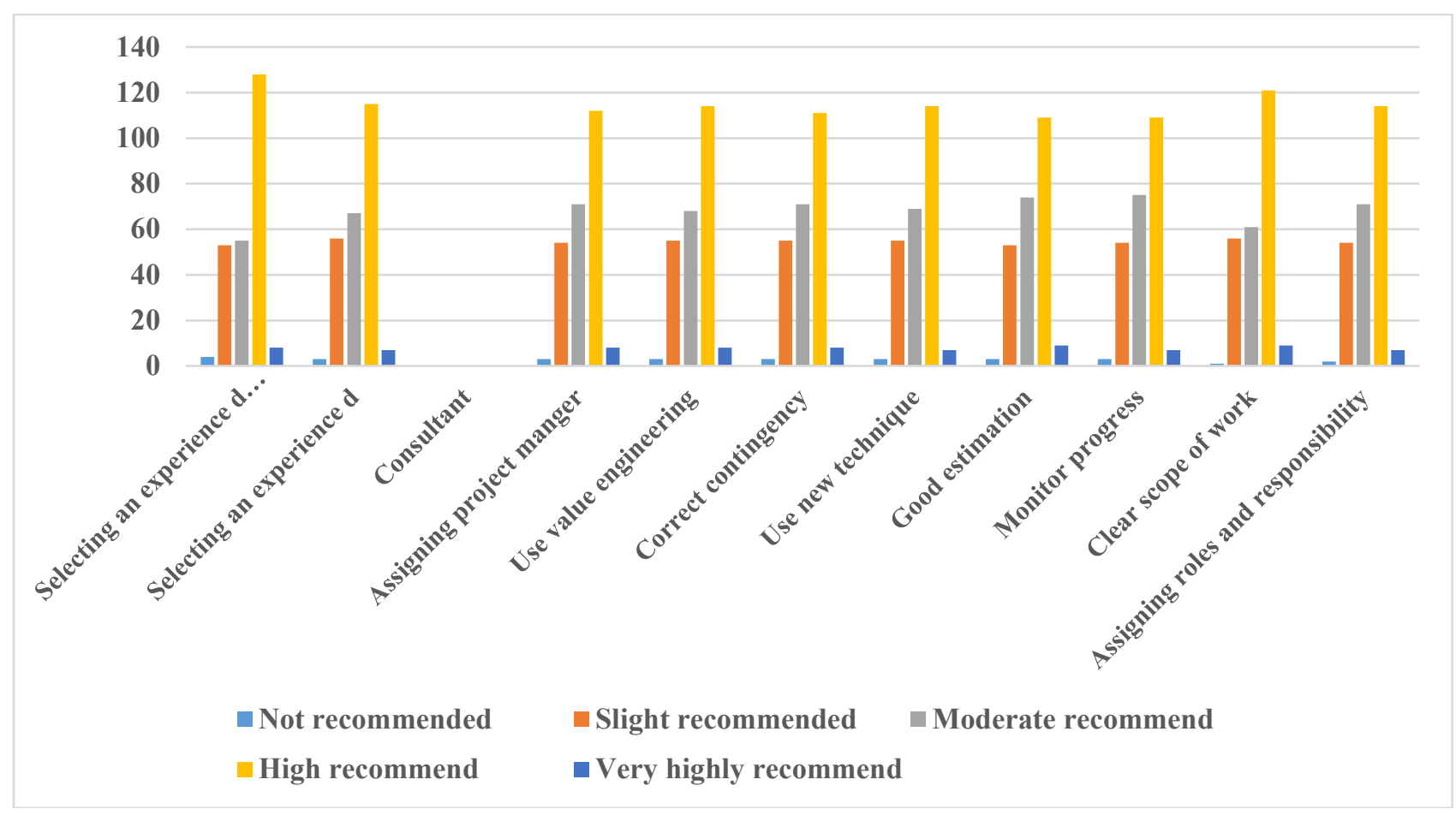

Figure 3: Cost overrun effective strategy

\section{Conclusion}

The results show that the most important factors that cause cost overrun in residential projects in the Sultanate of Oman arise from the increase in the price of materials and inaccurate cost estimate are at the highest rank followed by changing the specifications of the materials during construction. All reasons that cause risks to exceeding the cost of construction in residential projects have to be taken into account and managed in an appropriate manner. To improve the construction sector, project parties must know the factors that contribute to the development of the country's economy and its advancement in all fields because all sectors are linked with each other. Finally, recommendations are made that minimize the effects of the factors that cause construction cost overruns in residential projects in the Sultanate of Oman. As the results indicate, all factors cause the problem of exceeding the construction cost of residential projects, and each factor has an effect that differs from other factors. There are some goals that the research focused on which relate to construction cost overruns, cost trend and financial risks of residential buildings in Oman. This is a summary of each objective obtained through the results.

\section{References}

Abdel-Hafeez, M. M., El-Attar, S. S., \& Abdel-Hafeez, W. A. (2016). Factors Leading to Cost Overrun Occurrence in Construction Projects. Port Said Engineering Research Journal, 20(1).

Abusafiya, H. A., \& Suliman, S. M. (2017). Causes and Effects of Cost Overrun on Construction Project in Bahrain: Part I (Ranking of Cost Overrun Factors and Risk Mapping). Modern Applied Science, 11(7), 20.

Al-Hazim, N., \& Salem, Z. A. (2015). Delay and cost overrun in road construction projects in Jordan. International Journal of Engineering \& Technology, 4(2), 288. 
Aljohani, A., Ahiaga-Dagbui, D., \& Moore, D. (2017). Construction projects cost overrun: What does the literature tell us? International Journal of Innovation, Management and Technology, 8(2), 137.

Alzahrani, J. I., \& Emsley, M. W. (2013). The impact of contractors' attributes on construction project success: A post construction evaluation. International Journal of Project Management, 31(2), 313-322.

Daniel, E. (2016). The Usefulness of Qualitative and Quantitative Approaches and Methods in Researching Problem-Solving Ability in Science Education Curriculum. Journal of Education and Practice, 7(15), 91-100. https://doi.org/2222-288X

Jia, L. Z. (2015). Impact Of The Cost Overrun Factors On The Project Delay In Construction Industry, Pahang, Malaysia. Doctoral Dissertation, Universiti Malaysia Pahang.

Kim, S., Chang, S., \& Castro-Lacouture, D. (2020). Dynamic modeling for analyzing impacts of skilled labor shortage on construction project management. Journal of Management in Engineering, 36(1), 4019035.

Memon, A. H., Rahman, I. A., \& Azis, A. A. A. (2011). Preliminary study on causative factors leading to construction cost overrun. International Journal of Sustainable Construction Engineering and Technology, 2(1).

Plebankiewicz, E. (2018). Model of predicting cost overrun in construction projects. Sustainability, 10(12), 4387.

Reina, P., \& Angelo, W. J. (2002). Megaprojects need more study up front to avoid cost overruns. ENR, 249(3).

Reiter, S., Stewart, G., \& Bruce, C. (2010). Integrating qualitative and quantitative approaches in cross-cultural research. 16th Americas Conference on Information Systems 2010, AMCIS 2010, 6(June 2014), 4172-4180.

Roslan, N., Zainun, N. Y., \& Memon, A. H. (2015). Relevancy of factors and mitigation measures in controlling time and cost overrun towards Malaysian environment. Applied Mechanics and Materials, 773, 1007-1011.

Shehu, Z., Endut, I. R., Akintoye, A., \& Holt, G. D. (2014). Cost overrun in the Malaysian construction industry projects: A deeper insight. International Journal of Project Management, 32(8), 1471-1480.

Siemiatycki, M. (2018). The making and impacts of a classic text in megaproject management: The case of cost overrun research. International Journal of Project Management, 36(2), 362-371.

\section{Stuchlík, J. (2018). THE MAIN RISK FACTORS LEADING TO COST OVERRUN IN DELIVERY OF CZECH PUBLIC BUILDING PROJECTS.}

Subramani, T., Sruthi, P. S., \& Kavitha, M. (2014). Causes of cost overrun in construction. IOSR Journal of Engineering, 4(6), 1-7. 